\title{
BMJ Open Effect of mobile application-based versus DVD-based CPR training on students' practical CPR skills and willingness to act: a cluster randomised study
}

\author{
Anette Nord, ${ }^{1}$ Leif Svensson, ${ }^{2}$ Håkan Hult, ${ }^{3}$ Susanne Kreitz-Sandberg, ${ }^{4}$ \\ Lennart Nilsson ${ }^{1}$
}

To cite: Nord A, Svensson L, Hult $\mathrm{H}$, et al. Effect of mobile application-based versus DVD-based CPR training on students' practical CPR skills and willingness to act: a cluster randomised study. BMJ Open 2016;6:e010717. doi:10.1136/bmjopen-2015010717

- Prepublication history and additional material is available. To view please visit the journal (http://dx.doi.org/ 10.1136/bmjopen-2015010717).

Received 30 November 2015 Revised 3 March 2016 Accepted 10 March 2016

CrossMark

For numbered affiliations see end of article.

Correspondence to Dr Lennart Nilsson; lennart.nilsson@liu.se

\section{ABSTRACT}

Objectives: The aim was to compare students' practical cardiopulmonary resuscitation (CPR) skills and willingness to perform bystander $\mathrm{CPR}$, after a 30 min mobile application (app)-based versus a 50 min DVD-based training.

Settings: Seventh grade students in two Swedish municipalities.

Design: A cluster randomised trial. The classes were randomised to receive app-based or DVD-based training. Willingness to act and practical CPR skills were assessed, directly after training and at 6 months, by using a questionnaire and a PC Skill Reporting System. Data on CPR skills were registered in a modified version of the Cardiff test, where scores were given in 12 different categories, adding up to a total score of 12-48 points. Training and measurements were performed from December 2013 to October 2014. Participants: 63 classes or 1232 seventh grade students (13-year-old) were included in the study. Primary and secondary outcome measures: Primary end point was the total score of the modified Cardiff test. The individual variables of the test and self-reported willingness to make a life-saving intervention were secondary end points.

Results: The DVD-based group was superior to the app-based group in CPR skills; a total score of 36 (33$38)$ vs $33(30-36)$ directly after training $(p<0.001)$ and $33(30-36)$ and $31(28-34)$ at 6 months $(p<0.001)$, respectively. At 6 months, the DVD group performed significantly better in 8 out of 12 CPR skill components. Both groups improved compression depth from baseline to follow-up. If a friend suffered cardiac arrest, $78 \%$ (DVD) versus $75 \%$ (app) would do compressions and ventilations, whereas only $31 \%$ (DVD) versus $32 \%$ (app) would perform standard CPR if the victim was a stranger.

Conclusions: At 6 months follow-up, the 50 min DVD-based group showed superior CPR skills compared with the $30 \mathrm{~min}$ app-based group. The groups did not differ in regard to willingness to make a life-saving effort.

\section{Strengths and limitations of this study}

- Largest randomised study to compare cardiopulmonary resuscitation (CPR) training methods (mobile application vs DVD) in students.

- The intervention was carried out in two major municipalities with schools from all socioeconomic areas and included $86 \%$ of eligible students.

- Outcome measures of practical CPR skills and willingness to act were evaluated directly after training and at 6 months.

- The two CPR training methods differed in duration (30 vs $50 \mathrm{~min}$ ), and thus we cannot differentiate between effects caused by type of training as opposed to duration of training.

\section{INTRODUCTION}

The incidence of out-of-hospital cardiac arrest (OHCA) in Sweden is approximately 54 per 100000 persons per year. ${ }^{1}$ A majority of all OHCA occur at home, where the prognosis is poorer compared with cardiac arrests occurring at other locations in the community. $^{2}$ Early cardiopulmonary resuscitation (CPR) increases the chance of survival two to three times. $^{3-5}$ Therefore, it is important that as many individuals as possible in the community acquire sufficient CPR skills.

The Swedish school curriculum specifies since 2011 that CPR skills are a core content in grade 7-9 (age 13-15) ${ }^{6}$ Each school decides how the education is offered; theoretical or practical, as one occasion or repeatedly. A statement from the European Patient Safety Foundation (EuPSF), the European Resuscitation Council (ERC), the International Liaison Committee on Resuscitation (ILCOR) and the World Federation of Societies of Anaesthesiologists (WFSA), approved by the 
WHO, recommends that all schoolchildren receive CPR training every year from the age of $12 .{ }^{7}$ If all students receive practical CPR training in school, a large proportion of the population will have basic skills within a few decades. Such a situation could potentially increase CPR intervention of bystanders in OHCA and have a significant impact on public health. ${ }^{7-12}$

Brief DVD-based courses are successful in teaching CPR skills. ${ }^{12-16}$ How short and simplified the training can be without negatively affecting students' skills and their willingness to act is, however, largely unknown. ${ }^{12}$ There are plenty of different mobile applications (app) intended to spread how to perform CPR. An app is easily accessible and the format might appeal to young people. The aim of this study was to evaluate alternative CPR training methods by comparing the practical CPR skills and the willingness to act in 13-year-old students, directly after a $30 \mathrm{~min}$ app-based or a $50 \mathrm{~min}$ DVD-based training session, and at 6 months of follow-up.

\section{METHODS}

\section{Study population and design}

In accordance with the Swedish school curriculum, ${ }^{6}$ the intervention was applied in grade 7 (13-year-old students). Invitations to participate in the study were sent to the headmasters of all council schools in two municipalities (140000 inhabitants). Eighteen of 24 schools agreed to participate. Four schools did not respond and two had CPR education only for grade 9. Prior to the study, students and their guardians obtained a letter with study information. Study participation of the individual students was completely voluntary and all participants gave oral informed consent.

Inclusion criteria: Seventh grade student in one of the participating schools. Exclusion criteria: Student does not want to participate, student with a physical handicap that significantly limited the physical performance, classes of students with development disabilities (these classes are age integrated and have fewer students per class).

The study used a cluster randomised design. ${ }^{17} \mathrm{~A}$ randomisation list was generated by an independent statistician and each of the 63 participating classes was randomly assigned to one of the main interventions: app-based or DVD-based education. In addition to the main intervention, some classes were randomised to various additional interventions, which were equally distributed in both groups. Ten classes were randomly assigned to perform a practical test only at 6 months. Thus, more students participated at the 6-month retest (figure 1). In the framework of this study, the additional interventions have not been analysed. Training and measurements were performed from December 2013 to October 2014.

\section{CPR education}

CPR education was performed in accordance with the ERC guidelines $2010{ }^{18}$ Training was given to the entire class together. Classes consisted of 14-29 students. All participants in both intervention groups used an individual training manikin, MiniAnne, during the training. Ten teachers were previous CPR instructors and 19 teachers received a $5 \mathrm{~h}$ education to become CPR instructors. All teachers obtained individual oral and written information to ensure that they were up to date with present CPR guidelines and training. The teachers acted as facilitators; they introduced the lesson, gave advice on the fly, answered questions and completed the course. For the app-based method, the students practised independently by using eight images with related text in a mobile application; introduction, checks responsiveness, opens the airway, checks respiration, alarm, chest compressions, ventilations and CPR 30:2. ${ }^{19}$ For the DVD-based method, the whole class practised CPR and recovery position together, based on instructions from a 31 min DVD. A total of 14 cycles of compressions and ventilations were carried out. The DVD and app are produced by the Swedish Resuscitation Council.

\section{Assessment}

Previous studies indicate that CPR skills can deteriorate already in 3-6 months. ${ }^{12}{ }^{20}$ In the present trial, CPR skills and willingness to act were evaluated directly after training and at 6 months, in order to assess both the immediate and long-term effects of the education. The 6-month follow-up was carried out without prior notice.

Laerdal PC Skill Reporting System V.2.4, linked to resuscitation manikin ResusciAnne, was used to automatically measure quantitative data; compression-ventilation ratio, hand position, compression depth, total number of compressions and ventilations, ventilation volume, handsoff time, compression rate and incomplete release. The participants' actions regarding check responsiveness, check respiration and call for help were assessed by direct observation of the investigator (AN). Collected data were recorded directly into a scoring sheet, which was a modified version of the validated Cardiff test. ${ }^{21}$ A score was given in each category and added up to a total score of 12-48 points. All categories of the scoring sheet are described in detail in online supplementary file 1 . The tests were not filmed because several students of a prestudy experienced filming as stressful. ${ }^{22}$

The ERC guidelines recommend a compression depth of 50-60 mm. ${ }^{18}$ The PC Skill Reporting System measures up to $60 \mathrm{~mm}$ compression depth. Highest score (six points) was given for an average compression depth of $50-59 \mathrm{~mm}$. Those who compressed $\geq 60 \mathrm{~mm}$ received five points. We chose to retain the six-point scale, as in previous studies, ${ }^{23}$ even though no one could receive three points, which would correspond to a $>65 \mathrm{~mm}$ compression depth.

The duration of the practical test was $3 \mathrm{~min}$. The optimal conduct was 30s to check responsiveness, check respiration and call for help, followed by $2.5 \mathrm{~min}$ of CPR. During the CPR, participants were expected to 


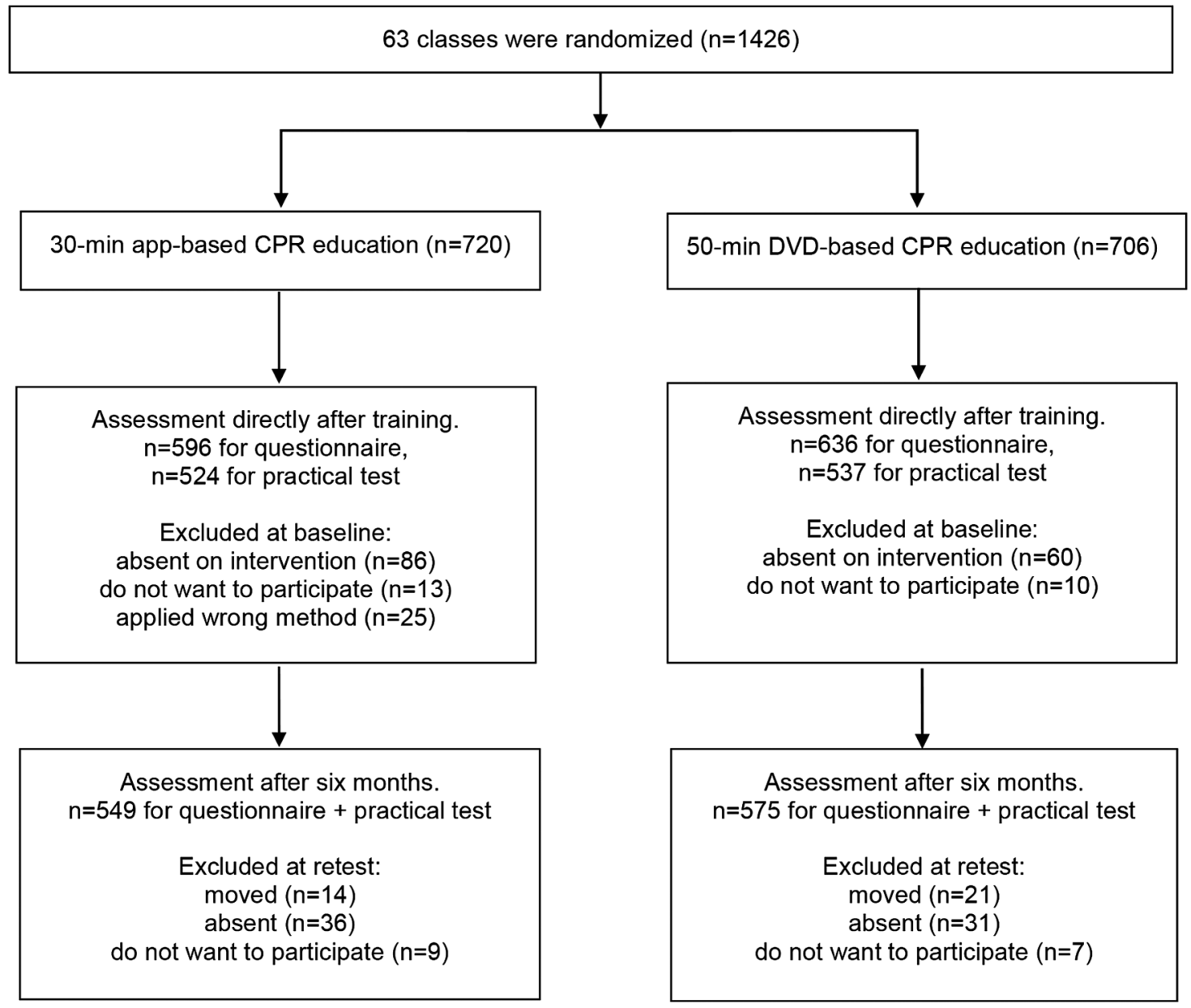

Figure 1 Flow chart on randomisation and inclusion. CPR, cardiopulmonary resuscitation.

perform at least five cycles of 30 compressions and two ventilations. The tests were conducted at the schools with one student at a time. The student was introduced to the test by the following story: 'You see an adult, someone you know, who collapsed in front of you. There is no one more on site. Show how you would act in a real life situation'. During the test, the test leader answered questions about the victim's condition only if relevant actions had already been carried out. Directly after the practical test, students received individual constructive feedback from the investigator for $2 \mathrm{~min}$. The students then answered a fixed-response questionnaire, where questions were asked about background factors and willingness to act. A majority of students responded to the survey online and each question had to be answered in order to proceed to the next. Two of the questions allowed the student to add their own comments. Prior to our study, the comprehension of the questionnaire was tested and found satisfactory in a separate cohort of 175 students. The questionnaire is included in online supplementary file 2 .

The investigator (AN) is a registered CPR instructor, experienced in the modified Cardiff test. The investigator was blinded to the allocated training method of the students.

\section{Study outcome measures}

The primary end point was the total score of the modified Cardiff test. The total score was calculated by adding the individual scores of the 12 different categories (checks responsiveness by talking, checks responsiveness by shaking, opens the airway, checks respiration, calls for help or dials 112, compression/ventilation ratio, hand position during compression, average compression depth, total compression counted, average ventilation volume, total ventilation counted, total hands-off time) assessed by the practical test. The individual categories of the test and self-reported willingness to make a lifesaving intervention were secondary end points.

\section{Statistical plan and analyses}

Data are presented as the proportion (per cent), median (IQR) or mean (SD), as appropriate. Differences in proportions were analysed with Pearson $\chi^{2}$ test. Differences in median total score between intervention groups were assessed using Mann-Whitney U test. Differences in mean chest compression data between intervention groups were analysed using unpaired $t$ test and differences within groups by paired $t$ test. By calculating the (individual total score-12)/ (maximum total score-12) $\times 100$, we received a measure 
of CPR quality in relation to optimal CPR. Multiple linear regression analyses for the total score of the modified Cardiff test were performed, including baseline covariates (gender, previous compression and ventilation training, previous experience of a cardiac arrest situation, school and class) as fixed effects. A $p$ value $<0.05$ was considered statistically significant.

Sample size calculations were based on data from a prestudy. ${ }^{22}$ To test for superiority with a $90 \%$ power to detect a two-point intergroup difference of the total score of the modified Cardiff test with a significance level of 0.05 , an effective sample size of 194 students would be needed. The intraclass correlation coefficient (95\% CI) was 0.20 (0.19 to 0.21$).{ }^{1724}$ The design effect, caused by cluster randomisation, was 4.22 . A number of 1061 and 1124 students performed the first and second tests, respectively. This corresponds to an effective sample size of 251 and 266, respectively, which is well above the 194 needed to reach a power of $90 \%$.

Analyses were performed using IBM SPSS V.21 and STATA V.13.1.

\section{RESULTS}

\section{Student sample}

A total of 1426 students from 63 seventh grade classes in 18 schools were randomised to receive a $30 \mathrm{~min}$ appbased or 50 min DVD-based CPR training. At baseline, 1232 students, corresponding to $86 \%$ of the eligible students, were included in the study. At 6 months, 1124 of these students completed the retest (figure 1). The baseline characteristics of the students are summarised in table 1.

\section{CPR skills}

The DVD group performed significantly better in terms of total score at both time points: at baseline 36 (33-38) vs $33(30-36)$ points $(\mathrm{p}<0.001)$ and at 6 months $33(30-$ $36)$ vs $31(28-34)$ points $(\mathrm{p}<0.001)$. For individual variables, the DVD group performed significantly better in 6 out of 12 immediately after training and 8 out of 12 at 6 months. Results of the modified Cardiff test are summarised in table 2.

Baseline characteristics were well matched between the intervention groups, except that students in the app group had significantly more previous ventilation training. Nevertheless, multiple linear regression analyses (including all baseline covariates) were performed to adjust for potential confounding, without any significant change in effect of the intervention being observed. The mean difference $(95 \% \mathrm{CI})$ in total score between intervention groups was 2.52 (2.03 to 3.02) points before and 2.55 (2.05 to 3.05) points after adjustment at the first test, and 1.61 (1.14 to 2.07) points before and 1.62 (1.15 to 2.09) points after adjustment at the 6 months test.

Data on variables reflecting the quality of chest compressions are presented in table 3. Of note, compression depth and hands-off time improved significantly from baseline to 6 months testing in the DVD and the app groups. Also, the DVD group performed significantly better in terms of chest compressions with complete release.

\section{Willingness to act}

For all variables reflecting willingness to act and potential obstacles, we found no significant differences between the DVD and the app groups. At 6 months follow-up, $81 \%$ in the DVD group and $78 \%$ in the app group were more confident to act compared with prior to training. Also, students considered themselves to have enough knowledge to do chest compressions (91\% in the DVD group and $92 \%$ in the app group) and to do rescue breaths $(74 \%$ in the DVD group and $70 \%$ in the app group). Six students described situations where they had made a life-saving intervention within 6 months after training. As shown in figure 2, there was a huge difference in willingness to intervene in an OHCA situation of a friend compared with a situation involving a stranger $(p<0.001)$. Fear to do harm $(8 \%$ in the DVD group and $7 \%$ in the app group) and fear of touching a stranger $(6 \%$ in the DVD group and $5 \%$ in the app group) are the two most common reasons for not wanting to perform chest compressions. Fear of disease transmission (8\% in the DVD group and $11 \%$ in the app group) and to touch a stranger $(10 \%$ in the DVD group and $8 \%$ in the app group) are the two most common reasons given for not wanting to perform ventilations on a stranger.

According to the questionnaire at 6 months, $31 \%$ of the students in the app group had looked at the app once or several times after the training session and $26 \%$ had shown it to another person.

Table 1 Students' characteristics

\begin{tabular}{lccc}
\hline & App $(\mathbf{n = 5 9 6 )}$ & DVD (n=636) & p Value \\
\hline Male & $285(48)$ & $294(46)$ & NS \\
Previous compression training & $192(32)$ & $171(27)$ & NS \\
Previous ventilation training & $158(26)$ & $113(18)$ & $<0.001$ \\
Previously experienced a cardiac arrest situation & $19(3)$ & $21(3)$ & NS \\
Number of schools in which methods were applied & 16 & NS \\
\hline
\end{tabular}

Values are presented as $n$ (\%). Differences in proportions between groups were analysed by Pearson $\chi^{2}$ test.

NS, not significant. 
Table 2 Assessment of CPR skills directly after app-based or DVD-based training (baseline) and at 6 months (retest)

\begin{tabular}{|c|c|c|c|c|c|c|}
\hline & $\begin{array}{l}\text { App, baseline } \\
(\mathrm{N}=524)\end{array}$ & $\begin{array}{l}\text { DVD, baseline } \\
(\mathrm{N}=537)\end{array}$ & p Value & $\begin{array}{l}\text { App, retest } \\
(\mathrm{N}=549)\end{array}$ & $\begin{array}{l}\text { DVD, retest } \\
(\mathrm{N}=575)\end{array}$ & p Value \\
\hline \multicolumn{7}{|c|}{ Checks responsiveness by talking } \\
\hline 2: Yes & $241(46)$ & $354(66)$ & \multirow{2}{*}{$<0.001$} & $127(23)$ & $213(37)$ & \multirow{2}{*}{$<0.001$} \\
\hline 1: No & $283(54)$ & $183(34)$ & & $422(77)$ & $362(63)$ & \\
\hline \multicolumn{7}{|c|}{ Checks responsiveness by shaking } \\
\hline 3: Yes & $353(67)$ & $376(70)$ & \multirow[t]{3}{*}{ NS } & $164(30)$ & $219(38)$ & \multirow[t]{3}{*}{0.004} \\
\hline 2: No & 169 (32) & $160(30)$ & & $385(70)$ & $356(62)$ & \\
\hline 1: Potentially dangerous & $2(<1)$ & $1(<1)$ & & 0 & 0 & \\
\hline \multicolumn{7}{|c|}{ Open airway_chin lift, head tilt } \\
\hline 5: Perfect & $6(1)$ & $23(4)$ & \multirow[t]{5}{*}{$<0.001$} & $3(1)$ & $9(2)$ & \multirow[t]{5}{*}{$<0.001$} \\
\hline 4: Acceptable & $46(9)$ & $110(20)$ & & 9 (2) & 17 (3) & \\
\hline 3: Attempted other & $3(<1)$ & $1(<1)$ & & 0 & $1(<1)$ & \\
\hline 2: Only one element & $130(25)$ & $186(35)$ & & $18(3)$ & $73(13)$ & \\
\hline 1: No & $339(65)$ & $217(40)$ & & $519(94)$ & 475 (83) & \\
\hline \multicolumn{7}{|c|}{ Checks respiration—see, listen, feel } \\
\hline 2: Yes & $388(74)$ & $396(74)$ & \multirow[t]{2}{*}{ NS } & $225(41)$ & 327 (57) & \multirow[t]{2}{*}{ NS } \\
\hline 1: No & $136(26)$ & $141(26)$ & & $324(59)$ & $248(43)$ & \\
\hline \multicolumn{7}{|l|}{ Dials 112} \\
\hline 2: Yes & $396(76)$ & $431(80)$ & \multirow[t]{2}{*}{ NS } & $411(75)$ & $458(80)$ & \multirow[t]{2}{*}{ NS } \\
\hline 1: No & $128(24)$ & $106(20)$ & & $138(25)$ & $117(20)$ & \\
\hline \multicolumn{7}{|l|}{ Compression/ventilation ratio } \\
\hline $4: 30: 2(28-32: 2)$ & $182(35)$ & $292(54)$ & \multirow[t]{4}{*}{$<0.001$} & $165(30)$ & $233(40)$ & $<0.001$ \\
\hline 3: Other ratio & $299(57)$ & $230(43)$ & & $319(58)$ & $304(53)$ & \\
\hline 2: Compressions only & $43(8)$ & $15(3)$ & & 65 (12) & $38(7)$ & \\
\hline 1: Ventilations only & 0 & 0 & & 0 & 0 & \\
\hline Hand position during comp & sion & & & & & \\
\hline 4: Correct & $50(10)$ & $68(13)$ & NS & $29(5)$ & $25(4)$ & NS \\
\hline 3: Other wrong & $312(60)$ & $333(62)$ & & $250(46)$ & 299 (52) & \\
\hline 2: Too low & $162(31)$ & $136(25)$ & & $270(49)$ & $251(44)$ & \\
\hline 1: Not attempted & 0 & 0 & & 0 & 0 & \\
\hline Average compression deptl & $\mathrm{nm})$ & & & & & \\
\hline $6: 50$ to 59 & $100(19)$ & $114(21)$ & NS & $183(33)$ & 224 (39) & 0.031 \\
\hline $5: \geq 60$ & $5(1)$ & $2(<1)$ & & $8(2)$ & $15(3)$ & \\
\hline 4: 35 to 49 & 255 (49) & $271(50)$ & & $239(44)$ & $242(42)$ & \\
\hline 2: 1 to 34 & $164(31)$ & $150(28)$ & & 119 (22) & $93(16)$ & \\
\hline 1: Not attempted & 0 & 0 & & 0 & 0 & \\
\hline Total compression counted & & & & & & \\
\hline 6: 140 to 190 & 179 (34) & $240(45)$ & $<0.001$ & $186(34)$ & $211(37)$ & 0.013 \\
\hline $5: \geq 191$ & $266(51)$ & $223(42)$ & & $253(46)$ & $285(50)$ & \\
\hline 4: 121 to 139 & $29(6)$ & $42(8)$ & & $51(9)$ & $37(6)$ & \\
\hline 3: 81 to 120 & $36(7)$ & $19(4)$ & & $43(8)$ & $38(7)$ & \\
\hline $2: 1$ to 80 & $14(3)$ & $13(2)$ & & $16(3)$ & $4(1)$ & \\
\hline 1: Not attempted & 0 & 0 & & 0 & 0 & \\
\hline Average ventilation volume & & & & & & \\
\hline 5: 500 to 600 & $27(5)$ & $31(6)$ & $<0.001$ & $19(4)$ & $22(4)$ & $<0.001$ \\
\hline $4: 1$ to 499 & $43(8)$ & $59(11)$ & & $50(9)$ & 49 (8) & \\
\hline $3: \geq 601$ & $207(40)$ & $357(66)$ & & $188(34)$ & $262(46)$ & \\
\hline $2: \overline{0}$ & 204 (39) & 75 (14) & & $225(41)$ & $204(36)$ & \\
\hline 1: Not attempted & $43(8)$ & $15(3)$ & & $67(12)$ & $38(7)$ & \\
\hline Total ventilation counted & & & & & & \\
\hline $5: 8$ to 12 & $117(22)$ & $249(46)$ & $<0.001$ & $98(18)$ & $139(24)$ & 0.001 \\
\hline 4: 1 to 7 & $112(21)$ & $130(24)$ & & $81(15)$ & $94(16)$ & \\
\hline $3: \geq 13$ & $48(9)$ & $68(13)$ & & $78(14)$ & $100(17)$ & \\
\hline $2: \overline{0}$ & 204 (39) & 75 (14) & & $225(41)$ & $204(36)$ & \\
\hline 1: Not attempted & $43(8)$ & $15(3)$ & & 67 (12) & $38(7)$ & \\
\hline Total 'hands-off' time (s) & & & & & & \\
\hline 4: $0-60$ & $122(23)$ & $56(10)$ & $<0.001$ & $196(36)$ & $164(28)$ & 0.018 \\
\hline 3: $61-90$ & $302(58)$ & $355(66)$ & & $278(51)$ & 339 (59) & \\
\hline
\end{tabular}


Table 2 Continued

\begin{tabular}{lcccccr}
\hline & $\begin{array}{l}\text { App, baseline } \\
(\mathbf{N = 5 2 4 )}\end{array}$ & $\begin{array}{l}\text { DVD, baseline } \\
(\mathbf{N = 5 3 7 )}\end{array}$ & p Value & $\begin{array}{l}\text { App, retest } \\
(\mathbf{N = 5 4 9 )}\end{array}$ & $\begin{array}{l}\text { DVD, retest } \\
(\mathbf{N}=\mathbf{5 7 5 )}\end{array}$ & p Value \\
\hline 2: $91-135$ & $97(18)$ & $117(22)$ & & $71(13)$ & $71(12)$ & \\
1: $136-180$ & $3(1)$ & $9(2)$ & & $4(1)$ & $1(<1)$ & \\
Total score & $33(30-36)$ & $36(33-38)$ & $<0.001$ & $31(28-34)$ & $33.0(30-36)$ & $<0.001$ \\
\hline
\end{tabular}

Results are presented as $\mathrm{n}(\%)$ or median (25th-75th centile). Differences in proportions between groups were analysed by Pearson $\chi^{2}$ test. Differences in total score between intervention groups were analysed by Mann-Whitney U test. $p$ Values $<0.05$ were considered statistically significant. The table lists the variable's best option at the top. All numbers are rounded to the nearest even integer.

CPR, cardiopulmonary resuscitation; NS, not significant.

\section{DISCUSSION}

The main findings of the present study are twofold. First, a 50 min DVD-based training method was superior to a $30 \mathrm{~min}$ app-based education in terms of teaching practical CPR skills to seventh grade students. Second, there was no significant difference in willingness to act between the app and DVD groups. The study was carried out in schools from all socioeconomic areas and included $86 \%$ of eligible students, strengthening the generalisability of our findings.

The total score of the modified Cardiff test differed significantly by $2-3$ points between the app and DVD groups on both occasions. The importance of this difference is unclear, since the size of a clinically relevant difference has yet to be established. The largest differences in favour of the DVD-based method were found for the following components: check responsiveness by talking, open airway, compression/ventilation ratio and ventilation. Three of these variables can be related; if students fail to create an open airway, they will fail with the ventilations, which result in the students making repeated attempts and thus losing the correct compression/ventilation ratio. Indeed, several studies have shown that a large proportion of participants after CPR training have limited knowledge on how to correctly perform a rescue breath. ${ }^{23} 2526$

The cause of the differences observed between the app and DVD groups in this study is unknown. This study was not designed to explain the cause of any potential differences. In both methods, the students trained individually on a MiniAnne manikin and the training did not include any planned interaction or cooperation with classmates. In the DVD-based method, all students practised the same task at the same time. It gave quantity of training and the teachers received an overview of the training and could easily see if a student did not follow the instructions. In the app-based method, the students could choose individually how many times they repeated the practical exercises. That makes it more difficult for the teacher to get an overview of the training and it is unclear if the students took responsibility and repeated the exercises until they felt they had mastered each part. The moving instructions of the DVD in combination with repeated training might be considered a strength of the DVD-based method. An advantage with the app method is that it can provide support in acute situations, and the app is also available after training has been completed, with the opportunity to repeat and to share with others. The DVD method has been applied for several years and has been revised and developed repeatedly. The app method is new and may need further development, for example, by specifying the number of repetitions to be performed during training. A weakness with both the app and the DVD methods is that no systematic and individual feedback was given to the students during training. The training was given to the entire class at the same time, to easily fit into the school schedule, but at the expense of limited opportunity to give feedback. Feedback is known to be one of the most powerful influences on performance. ${ }^{27} 28$ The issue of feedback is essential and should be explored in future research.

In our study, practical CPR skills were significantly reduced from measurement directly after training to

Table 3 Chest compression data of the app and the DVD groups

\begin{tabular}{|c|c|c|c|c|c|c|}
\hline & $\begin{array}{l}\text { App directly after } \\
\text { training }(\mathrm{N}=524)\end{array}$ & $\begin{array}{l}\text { DVD directly after } \\
\text { training }(\mathrm{N}=537)\end{array}$ & p Value & $\begin{array}{l}\text { App at retest } \\
(\mathrm{N}=549)\end{array}$ & $\begin{array}{l}\text { DVD at retest } \\
(\mathrm{N}=575)\end{array}$ & p Value \\
\hline CC depth $(\mathrm{mm})$ & $40(11)$ & $40(11)$ & NS & $44(10)^{*}$ & $46(10)^{*}$ & 0.002 \\
\hline $\mathrm{CC}$ rate $(\mathrm{n} / \mathrm{min})$ & $111(27)$ & $112(20)$ & NS & $100(27)^{\star}$ & $104(22)^{\star}$ & 0012 \\
\hline $\mathrm{CC}$ rate $100-120 / \mathrm{min}$ & 149 (28) & $232(43)$ & $<0.001$ & $166(30)$ & 217 (38) & 0.008 \\
\hline $\mathrm{CC}$ with complete release & $387(74)$ & $446(83)$ & $<0.001$ & $416(76)$ & $476(83)$ & 0.004 \\
\hline Total hands-off time (s) & $73(21)$ & 81 (19) & $<0.001$ & $68(24)^{\star}$ & $69(22)^{\star}$ & NS \\
\hline
\end{tabular}

Values are presented as mean (SD) or $n(\%)$. Differences in proportions were analysed by Pearson $\chi^{2}$ test. Differences between intervention groups were analysed by unpaired $t$ test. Differences between baseline and retest were analysed by paired $t$ test, where * indicates $p<0.001$. CC, chest compression; NS, not significant. 
App

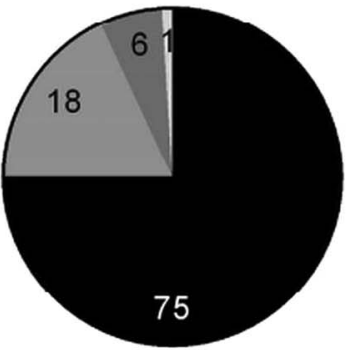

App

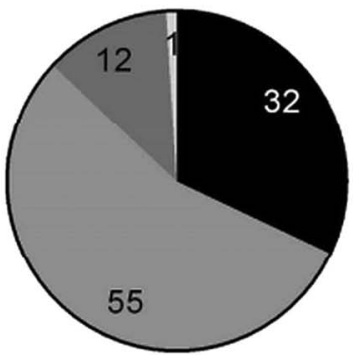

DVD

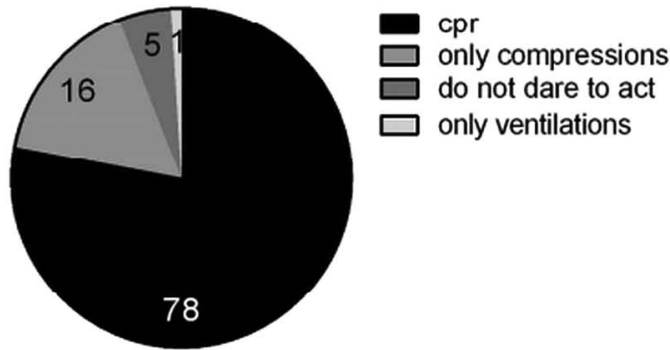

DVD

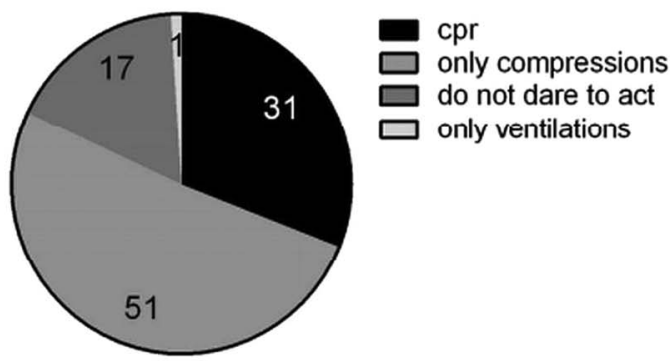

Figure 2 Students' willingness to act if a friend suffers a cardiac arrest (upper panel) or if a stranger suffers a cardiac arrest (lower panel), as assessed 6 months after training. Values are given as per cent. Numbers are $n=549$ (app) and $n=575$ (DVD). $\mathrm{CPR}$, cardiopulmonary resuscitation.

6 months in both groups, which is similar to other studies. ${ }^{12}{ }^{20}$ In evaluating the CPR skills of the participants, we consider the results of the 6 months test to be of most importance, since these results reflect the longterm knowledge of the students. At 6 months, the DVD group obtained 58\% (33 points) and the app group $53 \%$ (31 points) of the maximum score, which is comparable with results of previous studies where seventh grade students performed $50 \%$ and adults $57-61 \%$ of the total score at 3-4 months after training. ${ }^{23} 25$

At the 6 months retest, both groups performed 4$5 \mathrm{~mm}$ deeper compressions compared with baseline. Previous studies show significant correlations between age, weight, height and compression depth. ${ }^{20}$ 29-31 However, in our study, it is unlikely that the strength of the students improved so much during 6 months as to explain the improved compression depth. Interestingly, similar results were observed in a prestudy, despite the retest being carried out after only 3 months. ${ }^{22}$ The oral feedback received by the students after the first test might have helped them to perform deeper chest compressions at the retest. Also, we cannot exclude the fact that the students at the retest were more familiar with the test doll and thus performed better. The proportion of students who applied incorrect hand position was high in both groups (at retest; 96\% vs 95\%). Previous studies, using diverse definitions, indicate a large variation (13-90\%) regarding correct hand position. ${ }^{23} 25293132$ Isbye $e t a l^{25}$ argue that the definition of 'incorrect hand position' is important when results are compared. The poor hand positioning in our study could possibly be explained by the fact that the compression place on MiniAnne, used during training, is 'marked' and thus the students might not reflect on correct hand positioning. At the test situation, however, the ResuciAnne has a 'whole chest skin' without marking.

Students generally have a positive attitude towards CPR training. ${ }^{12} \quad 31 \quad 33-35$ Practical training reduces concern at making mistakes, as well as increases selfreported confidence and willingness to intervene. ${ }^{33} 3637$ In our study, there was no significant difference in willingness to act between the app and DVD groups. However, we found a huge difference in willingness to intervene in a cardiac arrest situation of a friend compared with a situation involving a stranger. This is in accordance with previous studies, ${ }^{33} 3638$ and needs to be considered when creating educations. Common reasons for not starting CPR include lack of CPR knowledge and fear of not being able to do CPR correctly. ${ }^{33} 3638{ }^{39} \mathrm{In}$ our study, fear to do harm was one of the most common reasons for not wanting to perform chest compressions on a stranger. In CPR training, it is important to emphasise that 'laypeople cannot do anything wrong-the only wrong thing would be to do nothing, 7 A common barrier for ventilation was fear of disease transmission. Therefore, it is important to emphasise that the risk of disease transmission during CPR intervention is very low. ${ }^{40} 41$

\section{Clinical implication}

This study indicates that a DVD-based CPR training method might be preferable when teaching seventh grade students, although the clinical relevance of a 23-point difference is unclear. Further studies are needed to identify optimal and alternative teaching methods. 


\section{Study limitations}

First, we cannot exclude that the duration of the training (30 vs $50 \mathrm{~min}$ ), rather than the type of training per se, accounted for the differences observed in the tests. However, in the app-based education, training on recovery position was excluded. Thus, there was time enough for the students in the app group to carry out the same amount of cycles of compressions and ventilations as in the DVD group.

Second, the questionnaire used to evaluate willingness to act contains only hypothetical questions. They do not fully answer how the students would act in a real situation.

Third, it is a risk that the instructors experience and/ or enthusiasm affects the learning. Therefore, the methods were standardised to ensure equivalent education, the teacher only had a role as a facilitator during the training, and the practical exercises were based on instructions from the app and the DVD, respectively.

Fourth, we cannot exclude the possibility of contamination between classes of the same school. However, a potential contamination is not expected to have a significant impact on the test results, since the hands-on training is by far the most important factor to acquire practical CPR skills. ${ }^{9}{ }^{20}$ Also, if contamination existed and had an effect on test results, it would rather lessen than enhance any differences between groups.

Lastly, we do not know if the number of students in each class affects the outcome, but the instructor only had the role of a facilitator and previous studies have shown that larger DVD-based groups are performing equivalent to smaller traditional instructor-led groups. ${ }^{16}$

\section{CONCLUSION}

Overall, a $50 \mathrm{~min}$ DVD-based training seemed to be superior to a $30 \mathrm{~min}$ app-based education in terms of teaching practical CPR skills to seventh grade students. After CPR training, a majority of students, regardless of the training method, were willing to make a life-saving effort. However, only a third of the students would do both compressions and ventilations if a stranger suffered a cardiac arrest. This needs to be considered when creating educations.

\section{Author affiliations \\ ${ }^{1}$ Department of Medical and Health Sciences, Linköping University, Linköping, Sweden \\ ${ }^{2}$ Department of Medicine, Karolinska Institute, Stockholm, Sweden \\ ${ }^{3}$ Department of Clinical Science, Intervention and Technology, Karolinska Institute, Stockholm, Sweden \\ ${ }^{4}$ Department of Behavioural Sciences and Learning, Linköping University, Linköping, Sweden}

Acknowledgements The authors would like to thank all the students and teachers who participated in the study.

Contributors AN contributed to the study design, developed the modified Cardiff test and the questionnaire, conducted all measurements, analysed results and wrote the initial draft of the manuscript. LS contributed to the study design, developed the modified Cardiff test and revised the manuscript.
$\mathrm{HH}$ and SK-S contributed to the study design and revised the manuscript. LN contributed to the study design, developed the modified Cardiff test and the questionnaire, as well as analysed results and revision of the manuscript.

Funding The study was supported by the Foundation for cardiopulmonary resuscitation in Sweden, Swedish Resuscitation Council, Swedish Heart-Lung Foundation (award number 20130629) and the County Council of Östergötland.

\section{Competing interests None declared.}

Ethics approval The study was approved by the Regional Ethical Review Board of Linköping, Sweden (2013/358-31).

Provenance and peer review Not commissioned; externally peer reviewed.

Data sharing statement No additional data are available.

Open Access This is an Open Access article distributed in accordance with the Creative Commons Attribution Non Commercial (CC BY-NC 4.0) license, which permits others to distribute, remix, adapt, build upon this work noncommercially, and license their derivative works on different terms, provided the original work is properly cited and the use is non-commercial. See: http:// creativecommons.org/licenses/by-nc/4.0/

\section{REFERENCES}

1. Swedish cardiopulmonary resuscitation council. Swedish CPR registers annual report. 2014. http://www.hlr.nu/wp-content/uploads/ Svenska-HLR-registret-Arsrapport-2014.pdf (accessed 20 Sep 2015).

2. Herlitz J, Engdahl J, Svensson L, et al. Factors associated with an increased chance of survival among patients suffering from an out-of-hospital cardiac arrest in a national perspective in Sweden. Am Heart J 2005;149:61-6.

3. Holmberg M, Holmberg S, Herlitz J. Effect of bystander cardiopulmonary resuscitation in out-of-hospital cardiac arrest patients in Sweden. Resuscitation 2000;47:59-70.

4. Perkins GD, Handley AJ, Koster RW, et al. European Resuscitation Council guidelines for resuscitation 2015 section 2. Adult basic life support and automated external defibrillation. Resuscitation 2015;95:81-99.

5. Hasselqvist-Ax I, Riva G, Herlitz J, et al. Early cardiopulmonary resuscitation in out-of-hospital cardiac arrest. $N$ Engl J Med 2015;372:2307-15.

6. Swedish National Agency for Education. Swedish curriculum for the compulsory school, preschool class and the recreation centre. 2011. http://www.skolverket.se/publikationer?id=2687 (accessed 10 Oct 2015).

7. Kids Save Lives-Training School Children in Cardiopulmonary Resuscitation Worldwide. A Statement from the European Patient Safety Foundation, the European Resuscitation Council, the International Liaison Committee on Resuscitation and the World Federation of Societies of Anesthesiologists. http://www.ircouncil.it/ files/documenti/Documenti_nuovi_3/WHO_School_children_ statement 2015-1-22 FINÄL.pdf (accessed 10 Oct 2015).

8. Bohn A, Van Aken H, Lukas RP, et al. Schoolchildren as lifesavers in Europe-training in cardiopulmonary resuscitation for children. Best Pract Res Clin Anaesthesiol 2013;27:387-96.

9. Cave DM, Aufderheide TP, Beeson J, et al. Importance and implementation of training in cardiopulmonary resuscitation and automated external defibrillation in schools. Circulation 2011;123:691-706.

10. Bohn A, Lukas RP, Breckwoldt J, et al. Kids save lives': why schoolchildren should train in cardiopulmonary resuscitation. Curr Opin Crit Care 2015;21:220-5.

11. Connolly A, Toner $\mathrm{P}$, Connolly $\mathrm{D}$, et al. The 'ABC for life' programme -teaching basic life support in schools. Resuscitation 2007;72:270-9.

12. Greif R, Lockeyb AS, Conaghanc $P$, et al. European Resuscitation Council guidelines for resuscitation 2015 section 10. Education and implementation of resuscitation. Resuscitation 2015;95:288-301.

13. Batcheller AM, Brennan RT, Braslow A, et al. Cardiopulmonary resuscitation performance of subjects over forty is better following half-hour video self-instruction compared to traditional four-hour classroom training. Resuscitation 2000;43:101-10.

14. Lynch B, Einspruch EL, Nichol G, et al. Effectiveness of a 30-min CPR self-instruction program for lay responders: a controlled randomized study. Resuscitation 2005;67:31-43. 
15. Thorén AB, Axelsson ÅB, Herlitz J. DVD-based or instructor-led CPR education-a comparison. Resuscitation 2007;72:333-6.

16. Isbye DL, Rasmussen LS, Lippert FK, et al. Laypersons may learn basic life support in $24 \mathrm{~min}$ using a personal resuscitation manikin. Resuscitation 2006;69:435-42.

17. Donner A, Klar N. Design and analysis of cluster randomization trials in health research. London: Arnold Publishing, 2000.

18. Koster RW, Baubin MA, Bossaert LL, et al. European Resuscitation Council guidelines for resuscitation 2010 section 2 . Adult basic life support and use of automated external defibrillators. Resuscitation 2010;81:1277-92.

19. Rädda hjärtat. http://www.hjart-lungfonden.se/raddahjartat/ (accessed 10 Oct 2015).

20. Plant N, Taylor K. How best to teach CPR to schoolchildren: a systematic review. Resuscitation 2013;84:415-21.

21. Whitfield RH, Newcombe RG, Woollard M. Reliability of the Cardiff test of basic life support and automated external defibrillation version 3.1. Resuscitation 2003;59:291-314.

22. Nord A. CPR training in 7th grade. Instructor-led or DVD-based, which teaching method is most effective? [master]. Linköpings University, 2013:3. http://urn.kb.se/resolve?urn=urn:nbn:se:liu: diva-117856 (accessed 10 Oct 2015).

23. Nielsen AM, Isbye DL, Lippert FK, et al. Distributing personal resuscitation manikins in an untrained population: how well are basic life support skills acquired? Emerg Med J 2012;29:587-91.

24. Killip S, Mahfoud Z, Pearce K. What is an intracluster correlation coefficient? Crucial concepts for primary care researchers. Ann Fam Med 2004;2:204-8.

25. Isbye DL, Meyhoff CS, Lippert FK, et al. Skill retention in adults and in children 3 months after basic life support training using a simple personal resuscitation manikin. Resuscitation 2007;74:296-302.

26. Van Raemdonck V, Monsieurs KG, Aerenhouts D, et al. Teaching basic life support: a prospective randomized study on low-cost training strategies in secondary schools. Eur J Emerg Med 2014;21:284-90.

27. Hattie J. Visible learning: a synthesis of over 800 meta-analyses relating to achievement. New York: Routledge, 2009.

28. Wollenschlager M, Hattie J, Machts $\mathrm{N}$, et al. What makes rubrics effective in teacher-feedback? Transparency of learning goals is not enough. Contemp Educ Psychol 2016;44-45:1-11.

29. Jones I, Whitfield $\mathrm{R}$, Colquhoun $\mathrm{M}$, et al. At what age can schoolchildren provide effective chest compressions? An observational study from the Heartstart UK schools training programme. BMJ 2007;334:1201.

30. Abelairas-Gómez C, Rodríguez-Núñez A, Casillas-Cabana M, et al. Schoolchildren as life savers: at what age do they become strong enough? Resuscitation 2014;85:814-19.

31. Naqvi S, Siddiqi R, Hussain SA, et al. School children training for basic life support. J Coll Physicians Surg Pak 2011:21:611-15.

32. Reder S, Cummings P, Quan L. Comparison of three instructional methods for teaching cardiopulmonary resuscitation and use an automatic external defibrillator to high school students. Resuscitation 2006;69:443-53.

33. Kanstad BK, Nilsen SA, Fredriksen K. CPR knowledge and attitude to performing bystander CPR among secondary school students in Norway. Resuscitation 2011;82:1053-9.

34. Petrić J, Malički M, Marković D, et al. Students' and parents' attitudes toward basic life support training in primary schools. Croat Med J 2013;54:376-80.

35. Berthelot S, Plourde M, Bertrand I, et al. Push hard, push fast: quasi-experimental study on the capacity of elementary schoolchildren to perform cardiopulmonary resuscitation. Scand $J$ Trauma Resusc Emerg Med 2013;21:41.

36. Cho GC, Sohn YD, Kang KH, et al. The effect of basic life support education on laypersons' willingness in performing bystander hands only cardiopulmonary resuscitation. Resuscitation 2010;81:691-4.

37. Bohn A, Van Aken H, Möllhoff T, et al. Teaching resuscitation in schools: annual tuition by trained teachers is effective starting at age 10. A four-year prospective cohort study. Resuscitation 2012;83:619-25.

38. Omi W, Taniguchi T, Kaburaki T, et al. The attitudes of Japanese high school students toward cardiopulmonary resuscitation. Resuscitation 2008;78:340-5.

39. Swor R, Khan I, Domeier R, et al. CPR training and CPR performance: do CPR-trained bystanders perform CPR? Acad Emerg Med 2006;13:596-601.

40. Mejicano G, Maki D. Infections acquired during cardiopulmonary resuscitation: estimating the risk and defining strategies for prevention. Ann Intern Med 1998;129:813-28.

41. Soar J, Mancini ME, Bhanji F, et al. Part 12: education, implementation, and teams 2010 international consensus on cardiopulmonary resuscitation and emergency cardiovascular care science with treatment recommendations. Resuscitation 2010;81 (Suppl 1):e288-330. 